\title{
Role of basophils in rheumatoid arthritis (Review)
}

\author{
PEI TANG ${ }^{1}$, QIUHUA CHEN ${ }^{2}$, QIAOFEN LAN ${ }^{1}$, YANWEN CHEN $^{3}$, HAIJUAN YANG $^{3}$, \\ NING AN ${ }^{3}$, HAIYAN XIAO ${ }^{4}$, HUAFENG LIU ${ }^{3}$, PING WU ${ }^{1}$, TONG XIE ${ }^{2}$ and QINGJUN PAN ${ }^{3}$ \\ ${ }^{1}$ Clinical Research Center; ${ }^{2}$ Department of Rheumatism; ${ }^{3}$ Institute of Nephrology, \\ Affiliated Hospital of Guangdong Medical College, Zhanjiang, Guangdong 524001, P.R. China; \\ ${ }^{4}$ Cancer Center, Georgia Regents University, Augusta, GA 30912, USA
}

Received June 23, 2014; Accepted February 10, 2015

DOI: $10.3892 /$ etm.2015.2312

\begin{abstract}
The T helper (Th)1/Th2 imbalance plays a crucial role in the development of rheumatoid arthritis (RA). It is well known that basophils can affect the Th1/Th2 balance by enhancing the Th2 response, while impairing the Th1 response, which is known to be involved in the development of a number of diseases. However, limited information is available with regard to the role of basophils in RA. Decreased levels of circulating basophils and a dominant Th1 response have been reported in adult patients with RA, while children with juvenile RA have been largely found to have increased levels of circulating basophils and a dominant Th2 response. Furthermore, the circulating basophils in the two conditions have an activated phenotype and are associated with disease activity. In addition, a longitudinal study found the $\mathrm{Th} 2$ response was dominant in the early stages of RA, while the Th1 response was dominant in long-term chronic RA. These observations indicate that basophils may be involved in the development of RA by affecting the Th1/Th2 balance, particularly in the early stages of RA. Therefore, targeting basophils may be a novel therapeutic strategy for the treatment of RA; however, further investigation is required.
\end{abstract}

\section{Contents}

1. Role of the Th1/Th2 response in RA

2. Role of basophils in the Th1/Th2 response

3. Basophils may play a key role in the development of RA

4. Number and activation degree of peripheral blood basophils in JRA

Correspondence to: Mr. Ping Wu, Clinical Research Center, Affiliated Hospital of Guangdong Medical College, 57 South Renming Avenue, Zhanjiang, Guangdong 524001, P.R. China E-mail: wping62@126.com

Dr Qingjun Pan, Institute of Nephrology, Affiliated Hospital of Guangdong Medical College, 57 South Renming Avenue, Zhanjiang, Guangdong 524001, P.R. China

E-mail: stilwapan@gmail.com

Key words: basophil, T helper 1/T helper 2, rheumatoid arthritis
5. Mechanisms underlying periphery basophil activation in RA

\section{Role of the Th1/Th2 response in $R A$}

Rheumatoid arthritis (RA) is an autoimmune disease that is characterized by persistent intense immunological activity, local destruction of bone and cartilage, and a variety of systemic manifestations (1). Although the pathogenesis is yet to be fully resolved, the Thelper (Th)1/Th2 response is known to play an important role in the development of RA (2).

Adult patients with active RA have been shown to have a dominant Th1 cell-mediated immune response (Th1 advantage), as reported in experimental, clinical and epidemiological studies in vivo and in vitro $(1,2)$. In addition, inducing a Th2-type response was found to be beneficial for the treatment of RA in an in vivo rat model induced by type II collagen, while a drug-induced Th2 response was able to inhibit the inflammation observed in RA induced by excessive Th1 responses in vitro (2). To date, studies investigating the balance of the Th1/Th2 response in peripheral blood mononuclear cells (PBMCs) for the clinical treatment of RA are limited, and reliable conclusions are yet to be established.

Children aged $<16$ years suffering from RA are classified as having juvenile RA (JRA), which is now known as juvenile idiopathic arthritis (JIA). This condition is clinically and genetically distinct from that observed in adult patients (3). In previous studies on children with JIA, the majority of cases have presented with a dominant Th2 cell-mediated immune response (Th2 advantage) $(4,5)$. In addition, the longer the course of the disease, the more significant the Th2 response (5). Furthermore, treatment with Th1-type cytokines, such as interferon (IFN)- $\gamma$, may be useful for the control of JIA (6). However, a type 1 phenotype of synovial fluid $\mathrm{T}$ cells has also been identified in patients with JIA, suggesting a high IFN- $\gamma$ to interleukin (IL)-4 ratio in the synovial fluid, which indicates that specific activation events have occurred in the synovial $\mathrm{T}$ cells that may differ from PMBC T cells (7).

In addition, longitudinal studies in human patients with RA have revealed that the production of Th1/Th2-type cytokines in different stages, particularly in the early and late stages, are not the same, which suggests that there may be a shift in the Thl/Th2 balance at different development stages of RA. A Th2 response dominates in the PBMCs at 
early stages of RA, while long-term chronic RA exhibits a Th1 dominant response (8). Patients with early inflammatory arthritis, who subsequently developed RA, had a distinct but transient synovial fluid cytokine profile. The levels of type 2 cytokines, such as IL- 4 and IL-13, were significantly elevated in these patients within 3 months after symptom onset, as compared with the early arthritis patients who did not develop RA. In addition, this cytokine profile was not present in patients with established RA. By contrast, patients with non-rheumatoid persistent synovitis exhibited elevated levels of IFN- $\gamma$ at the initiation of the disease, which suggested that early synovitis destined to develop into RA may be characterized by a distinct and transient synovial fluid cytokine profile (9). However, in an adult patient with active RA, a dominant Th1 response was initially observed in the synovium, while a dominant Th2 response was observed in the PBMCs. Subsequently, a Th0 and Th1 response became dominant in the synovium, which was associated with disease inflammation (10).

Therefore, whether the Th1 or Th2 response is dominant in RA may depend on a variety of factors, including the age of the patients (JIA or RA), the stage of RA (early or late) and where the condition is located (PBMCs or synovial fluid). However, the mechanisms underlying the mediation of the imbalance in the Th1/Th2 response, particularly during the early stages of RA, remain unclear. In our clinical experience (data not published), the majority of newly diagnosed JIA cases were in the early stage, while the diagnosis of adult RA cases occurred predominantly during the interim or late stage of the disease. Based on these observations, a Th2 imbalanced response may be more important in the early stage of RA.

\section{Role of basophils in the Th1/Th2 response}

In recent years, research into the effector functions and immunoregulatory effects of basophils has made considerable progress with marked achievements (11). Falcone et al described the current insights into the roles of basophils in allergic responses and innate immunity (12). Karasuyama et al referred to basophils as a neglected minority that have gained a new respect following recent immunological studies (13).

The major immunoregulatory role of basophils in the regulation of the Th1/Th2 balance is the induction of Th2 immunity (14). Basophils are able to induce Th2 immunity by primarily secreting key Th2-inducing cytokines, namely IL-4 and thymic stromal lymphopoietin (TSLP), and by functioning as professional antigen presenting cells. Basophils are an efficient producer of Th2-type cytokines, such as IL-4 and IL-13, which are able to enhance the differentiation of Th0 into Th2 and inhibit the differentiation of Th0 to Th1 $(15,16)$. As such, following stimulation with allergens and innate IgE-dependent triggers or other activation methods, a novel immunoregulatory role of basophils has been identified in the regulation of the Th1/Th2 balance in vitro and in vivo (17). In addition, TSLP produced by basophils in the lymph nodes is important for the initiation of Th2 differentiation in vivo and in vitro (18). In a T cell-independent pathway, basophils induce an isotype switch toward $\operatorname{IgE}$ in human tonsillar B cells (19), which subsequently enhances the Th2-type humoral immune response (18). Therefore, basophils are able to regulate the Th1/Th2 balance by enhancing Th2 immunity, and may participate in the pathogenesis of various autoimmune diseases.

\section{Basophils may play a key role in the development of $\mathbf{R A}$}

A study that included 800 adult patients with RA found that the number of peripheral basophils was significantly decreased, although the cells were activated (20). In addition, the results of our study exhibited a similar trend in adult RA patients (21). However, the reason for the decreased number of peripheral basophils remains unclear, and the role of the decreased level of activated basophils in the development of RA, which is Th1 response dominant, requires further investigation.

A number of inflammatory effector cells, including macrophages and lymphocytes, have been observed to infiltrate into inflammatory sites in RA, such as synovial joint tissues. Furthermore, in animal models, such as guinea pigs, basophils have been shown to infiltrate into tissues during cutaneous hypersensitivity responses (cutaneous basophil hypersensitivity) $(22,23)$. Basophil infiltration has also been observed in allergen-induced late-phase cutaneous responses in human atopic subjects (24), and has been implicated in allergic human diseases (25). Previous observations in mice have clearly demonstrated that basophils are essential initiator cells of IgE-mediated chronic allergic inflammation (26), and are capable of functioning as a source of IL-4 and contributing to Th2-type immunity (27). An explanation for the concomitant recruitment of basophils may be due to the common expression of C-C chemokine receptor (CCR)3. Eotaxin 1 and 3, which are ligands of CCR3, are produced by several types of cell in response to Th2-type cytokines, such as IL-4 and IL-13.

In addition, basophils have been observed in the lymph node tissues of patients with systemic lupus erythematosus. Basophils may migrate to the lymph nodes due to the higher expression of the adhesion molecule, CD62L (28). Therefore, it was hypothesized that basophils become activated following migration to the lymph nodes or local inflammatory tissue, where they are involved in the inflammatory response, subsequently leading to a reduction in the number of peripheral blood basophils, and thus participating in the pathogenesis of adult RA (Fig. 1).

\section{Number and activation degree of peripheral blood basophils in JIA}

Athreya et al $(33,34)$ reported that peripheral basophils were increased in absolute number and in percentage in 11 out of 16 patients with JIA. The increase was particularly significant in children with active polyarticular arthritis.

JRA is an autoimmune disease which mainly causes the inflammation of joints. For the purpose of improving the description and classification of several forms of JRA, ILAR (International League of Associations for Rheumatology) recently redefined the disease. The name of JRA was changed to JIA. Furthermore, the classification of JIA has been expanded to include two further conditions, spondyloarthropathy and 


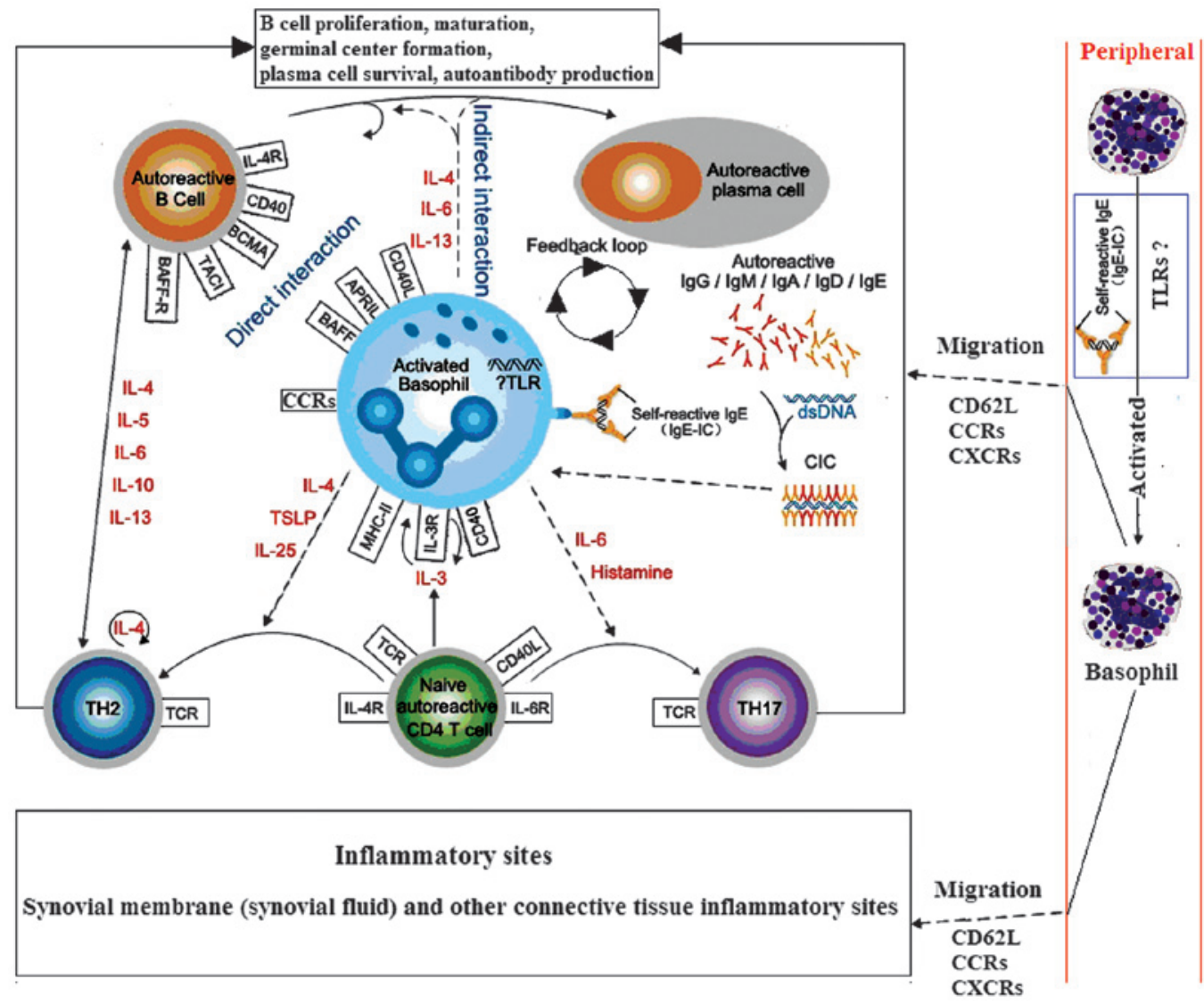

Figure 1. Hypothesis of the interactions between basophils, B and T cells during rheumatoid arthritis (RA; dotted line indicates the hypothesis sections). Autoreactive T and B cells trigger autoantibody production and CIC formation during RA, which may be mediated via activated basophils. These basophils may migrate from the blood into tissue sites, such as the lymph nodes, via the expression of CD62L, where they can interact with B and T cells, or inflammatory sites, via the expression of transcripts of CCR1, CCR2, CCR3, and CCR5 and CXCR1, CXCR2 and CXCR4, where they exert effector functions through the release of diverse, proinflammatory mediators (29-32). IL, interleukin; TSLP, thymic stromal lymphopoietin; BCMA, B cell maturation antigen; TACI, transmembrane activator and calcium modulator and cyclophilin ligand interactor; BAFF-R, B-cell activating factor receptor; TH, T helper; TCR, T-cell receptor; MHC, major histocompatibility complex; CCR, C-C chemokine receptor; CXCR, C-X-C chemokine receptor; TLR, Toll-like receptor; CIC, circulating antigen-antibody immune complexes.

psoriatic arthritis, which were not previously classified under JRA $(35,36)$.

\section{Mechanisms underlying periphery basophil activation in RA}

Basophils are an important source of Th2-type cytokines. Basophils collected from humans and mice have been shown to rapidly secrete large quantities of IL-4, as compared with $\mathrm{Th} 2$ cells, in response to various stimulations, including signaling through the FceRI (37-40). Moreover, upon IgE-receptor cross linking in basophils, a number of cell surface membrane antigens appear to be translocated from cytoplasmic membranes onto the cell surface (41-48). These upregulated cell surface membrane molecules include CD11b, CD13, CD63, CD107a, CD107b and CD203c (49).

In addition, in RA patients, higher levels of IgE type antibodies, which primarily form immune complexes (47) and circulating immune complexes (IgE-CIC) containing IgE, can be detected in the peripheral blood and synovial fluid (51-53). Furthermore, IgE-CIC-positive RA patients exhibit higher disease activity compared with negative patients (51). IgE-CIC can activate inflammatory effector cells, such as mast cells, neutrophils and mononuclear cells $(51,55)$, which subsequently promotes RA disease progression. These observations indicate that $\mathrm{IgE}$ immune complexes may mediate basophil activation in RA.

As reported, several animal models of arthritis are associated with a Th1 skew, and arthritis in such models can be ameliorated by therapeutic intervention aimed at restoring the Th1/Th2 balance (57-59). However, further investigation of the potential function of basophils in restoring the Th1/Th2 balance in RA, particularly in the early stage of RA, may be a novel therapeutic strategy in RA and requires further investigation.

Basophils may be involved in the development of RA by affecting the Th1/Th2 balance, particularly in the early stages of RA. Therefore, targeting basophils may be a novel therapeutic strategy for the treatment of RA; however, further studies are required to confirm this.

\section{Acknowledgements}

This study was supported by the National Natural Science Foundation of China (nos. 81202346 and 81471530), the Natural Science Foundation of Guangdong Province, China 
(no. S2013010011568) and the Zhanjiang Planning Project of Science and Technology (no. 2013B01086).

\section{References}

1. Harris ED Jr: Rheumatoid arthritis. Pathophysiology and implications for therapy. N Engl J Med 322: 1277-1289, 1990.

2. Schulze-Koops $\mathrm{H}$ and Kalden JR: The balance of Th1/Th2 cytokines in rheumatoid arthritis. Best Pract Res Clin Rheumatol 15: 677-691, 2001.

3. Woo P and Wedderburn LR: Juvenile chronic arthritis. Lancet 351: 969-973, 1998.

4. Raziuddin S, Bahabri S, Al-Dalaan A, et al: A mixed Th1/Th2 cell cytokine response predominates in systemic onset juvenile rheumatoid arthritis: immunoregulatory IL-10 function. Clin Immunol Immunopathol 86: 192-198, 1998.

5. Zhang Q, Zhang $\mathrm{H}$ and Dong Z: A study on immune response of Th1/Th2 in children with juvenile rheumatoid arthritis. Acta Acad Med Qingdao Univ 40: 134-136, 2004.

6. Tang AT, Lau YL, Jones B, et al: Cefadroxil reduces the production of IgE in a 3 year old asthmatic with juvenile rheumatoid arthritis. Allergol Immunopathol (Madr) 21: 131-135, 1993.

7. Wedderburn LR, Robinson N, Patel A, et al: Selective recruitment of polarized $\mathrm{T}$ cells expressing CCR5 and CXCR 3 to the inflamed joints of children with juvenile idiopathic arthritis. Arthritis Rheum 43: 765-774, 2000.

8. Gerli R, Bistoni O, Russano A, et al: In vivo activated T cells in rheumatoid synovitis. Analysis of Th1- and Th2-type cytokine production at clonal level in different stages of disease. Clin Exp Immunol 129: 549-555, 2002.

9. Raza K, Falciani F, Curnow SJ, et al: Early rheumatoid arthritis is characterized by a distinct and transient synovial fluid cytokine profile of T cell and stromal cell origin. Arthritis Res Ther 7: R784-R795, 2005.

10. Aarvak T, Chabaud M, Thoen J, et al: Changes in the Th1 or Th2 cytokine dominance in the synovium of rheumatoid arthritis (RA): a kinetic study of the Th subsets in one unusual RA patient. Rheumatology (Oxford) 39: 513-522, 2000.

11. Chirumbolo S: State-of-the-art review about basophil research in immunology and allergy: is the time right to treat these cells with the respect they deserve? Blood Transfus 10: 148-164, 2012.

12. Falcone FH, Zillikens D and Gibbs BF: The 21st century renaissance of the basophil? Current insights into its role in allergic responses and innate immunity. Exp Dermatol 15: 855-864, 2006.

13. Karasuyama H, Mukai K, Tsujimura Y and Obata K: Newly discovered roles for basophils: a neglected minority gains new respect. Nat Rev Immunol 9: 9-13, 2009.

14. Min B: Basophils induce Th2 immunity: Is this final answer? Virulence 1: 399-401, 2010.

15. Sokol CL, Barton GM, Farr AG and Medzhitov R: A mechanism for the initiation of allergen-induced $\mathrm{T}$ helper type 2 responses. Nat Immunol 9: 310-318, 2008.

16. Charles N, Watford WT, Ramos HL, et al: Lyn kinase controls basophil GATA-3 transcription factor expression and induction of Th2 cell differentiation. Immunity 30: 533-543, 2009.

17. Oh K, Shen T, Le Gros G and Min B: Induction of Th2 type immunity in a mouse system reveals a novel immunoregulatory role of basophils. Blood 109: 2921-2927, 2007.

18. Denzel A, Maus UA, Rodriguez Gomez M, et al: Basophils enhance immunological memory responses. Nat Immunol 9: 733-742, 2008

19. Gauchat JF, Henchoz S, Mazzei G, et al: Induction of human IgE synthesis in B cells by mast cells and basophils. Nature 365 : 340-343, 1993

20. Gao E and Xiang J: Basophils for the diagnosis of rheumatoid arthritis activity. Foreign Medical Sciences (Clinical Biochemistry and Laboratory Medicine Volume) 3: 40, 1986 (In Chinese).

21. Chen Q, Tang P, Lan Q, Xie T, Wu P and Pan Q: The number of activation of periphery basophils from patients with rheumatoid arthritis. The 19th National Annual Conference of the Chinese Rheumatology Association, pp162, 2014 (In Chinese).

22. Askenase PW: Cutaneous basophil hypersensitivity in contact-sensitized guinea pigs. I. Transfer with immune serum. J Exp Med 138: 1144-1155, 1973.

23. Askenase PW, Graziano F and Worms M: Basophils and mast cells. Immunobiology of cutaneous basophil reactions. Monogr Allergy 14: 222-235, 1979.
24. Ying S, Robinson DS, Meng Q, Barata LT, McEuen AR, Buckley MG, et al: C-C chemokines in allergen-induced late-phase cutaneous responses in atopic subjects: association of eotaxin with early 6-hour eosinophils, and of eotaxin-2 and monocyte chemoattractant protein-4 with the later 24-hour tissue eosinophilia and relationship to basophils and other C-C chemokines (monocyte chemoattractant protein-3 and RANTES). J Immunol 163: 3976-3984, 1999.

25. Mitchell EB and Askenase PW: Basophils in human disease. Clin Rev Allergy 1: 427-448, 1983.

26. Obata K, Mukai K, Tsujimura Y, Ishiwata K, Kawano Y, Minegishi Y, et al: Basophils are essential initiators of a novel type of chronic allergic inflammation. Blood 110: 913-920, 2007.

27. Sokol CL, Barton GM, Farr AG and Medzhitov R: A mechanism for the initiation of allergen-induced T helper type 2 responses. Nat Immunol 9: 310-318, 2008

28. Charles N, Hardwick D, Daugas E, Illei GG and Rivera J: Basophils and the Thelper 2 environment can promote the development of lupus nephritis. Nat Med 16: 701-707, 2010.

29. Yamada H, Hirai K, Miyamasu M, Iikura M, Misaki Y, Shoji S, Takaishi T, Kasahara T, Morita Y and Ito K: Eotaxin is a potent chemotaxin for human basophils. Biochem Biophys Res Commun 231: 365-368, 1997

30. Uguccioni M, Mackay CR, Ochensberger B, Loetscher P, Rhis S, LaRosa GJ, Rao P, Ponath PD, Baggiolini M and Dahinden CA: High expression of the chemokine receptor CCR3 in human blood basophils. Role in activation by eotaxin, MCP-4 and other chemokines. J Clin Invest 100: 1137-1143, 1997.

31. Krieger M, Brunner T, Bischoff SC, von Tscharner V, Walz A, Moser B, Baggiolini M and Dahinden CA: Activation of human basophils through the IL-8 receptor. J Immunol 149: 2662-2667, 1992.

32. Ochensberger B, Tassera L, Bifrare D, Rihs S and Dahinden CA: Regulation of cytokine expression and leukotriene formation in human basophils by growth factors, chemokines and chemotactic agonists. Eur J Immunol 29: 11-22, 1999.

33. Athreya BH, Moser G and Raghavan TE: Increased circulating basophils in juvenile rheumatoid arthritis. A preliminary report. Am J Dis Child 129: 935-937, 1975.

34. Athreya BH and Nichols WW: Basophils in juvenile rheumatoid arthritis. Pediatr Res 8: 397-397, 1974.

35. Petty RE, Southwood TR, Baum J, et al: Revision of the proposed classification criteria for juvenile idiopathic arthritis: Durban, 1997. J Rheumatol 25: 1991-1994, 1998.

36. Petty RE, Southwood TR, Manners P, et al: International League of Associations for Rheumatology Classification of juvenile idiopathic arthritis: second revision, Edmonton, 2001. J Rheumatol 31: 390-392, 2004

37. Seder RA, Paul WE, Dvorak AM, Sharkis SJ, Kagey-Sobotka A, Niv Y, et al: Mouse splenic and bone marrow cell populations that express high-affinity $\mathrm{Fc}$ epsilon receptors and produce interleukin 4 are highly enriched in basophils. Proc Natl Acad Sci USA 88: 2835-2839, 1991.

38. Schroeder JT, MacGlashan DW Jr and Lichtenstein LM: Human basophils: mediator release and cytokine production. Adv Immunol 77: 93-122, 2001.

39. Voehringer D, Shinkai K and Locksley RM: Type 2 immunity reflects orchestrated recruitment of cells committed to IL-4 production. Immunity 20: 267-277, 2004.

40. Min B, Prout M, Hu-Li J, et al: Basophils produce IL-4 and accumulate in tissues after infection with a Th2-inducing parasite. J Exp Med 200: 507-517, 2004.

41. Bühring HJ, Seiffert M, Giesert C, et al: The basophil activation marker defined by antibody $97 \mathrm{~A} 6$ is identical to the ectonucleotide pyrophosphatase/phosphodiesterase 3. Blood 97: 3303-3305, 2001

42. Hauswirth AW, Natter S, Ghannadan M, et al: Recombinant allergens promote expression of CD203c on basophils in sensitized individuals. J Allergy Clin Immunol 110: 102-109, 2002.

43. Platz IJ, Binder M, Marxer A, Lischka G, Valent $P$ and Bühring HJ: Hymenoptera-venom-induced upregulation of the basophil activation marker ecto-nucleotide pyrophosphatase/phosphodiesterase 3 in sensitized individuals. Int Arch Allergy Immunol 126: 335-342, 2001.

44. Bühring HJ, Streble A and Valent P: The basophil-specific ectoenzyme E-NPP3 (CD203c) as a marker for cell activation and allergy diagnosis. Int Arch Allergy Immunol 133: 317-329, 2004. 
45. Hennersdorf F, Florian S, Jakob A, et al: Identification of CD13, CD107a and CD164 as novel basophil-activation markers and dissection of two response patterns in time kinetics of IgE-dependent upregulation. Cell Res 15: 325-335, 2005.

46. Sonneck K, Baumgartner C, Rebuzzi L, et al: Recombinant allergens promote expression of aminopeptidase-n (CD13) on basophils in allergic patients. Int J Immunopathol Pharmacol 21: 11-21, 2008.

47. Chirumbolo S, Vella A, Ortolani R, et al: Differential response of human basophil activation markers: a multi-parameter flow cytometry approach. Clin Mol Allergy 6: 12, 2008.

48. Sainte-Laudy J and Ouk C: Use of lipid rafting for the analysis of human basophil activation by flow cytometry. Inflamm Res 59 (Suppl 2): S193-S195, 2010

49. Valent P: Basophil activation antigens: molecular mechanisms and clinical implications. Open Allergy J 3: 52-59, 2010.

50. Millauer N, Zuercher AW, Miescher SM, et al: High IgE in rheumatoid arthritis (RA) patients is complexed with anti-IgE autoantibodies. Clin Exp Immunol 115: 183-188, 1999.

51. De Clerck LS, Struyf NJ, Bridts CH and Stevens WJ: Activation of inflammatory cells by immune complexes containing IgE in serum and synovial fluid of patients with rheumatoid arthritis: a study using flow cytometric analysis. Ann Rheum Dis 50: 379-382, 1991

52. Van Offel JF, De Clerck LS and Kersschot IE: Cholesterol crystals and IgE-containing immune complexes in rheumatoid pericarditis. Clin Rheumatol 10: 78-80, 1991.
53. De Clerck LS, Struyf NJ, Bridts $\mathrm{CH}$, et al: IgE-containing immune complexes in synovial fluid of patients with rheumatoid arthritis. Clin Rheumatol 9: 176-181, 1990.

54. Bartholomew JS, Evanson JM and Woolley DE: Serum IgE anti-cartilage collagen antibodies in rheumatoid patients. Rheumatol Int 11: 37-40, 1991.

55. Permin H, Wiik A and Djurup R: Phagocytosis by normal polymorphonuclear leukocytes of immune complexes from serum of patients with Felty's syndrome and rheumatoid arthritis with special reference to IgE immune complexes. Acta Pathol Microbiol Immunol Scand C 92: 37-42, 1984.

56. Schuerwegh AJ, Ioan-Facsinay A, Dorjée AL, et al: Evidence for a functional role of $\mathrm{IgE}$ anticitrullinated protein antibodies in rheumatoid arthritis. Proc Natl Acad Sci USA 107: 2586-2591, 2010.

57. Müller B, Gimsa U, Mitchison NA, Radbruch A, Sieper J and Yin Z: Modulating the Th1/Th2 balance in inflammatory arthritis. Springer Semin Immunopathol 20: 181-196, 1998.

58. Nicholson LB and Kuchroo VK: Manipulation of the Th1/Th2 balance in autoimmune disease. Curr Opin Immunol 8: 837-842, 1996.

59. Joosten LA, Lubberts E, Durez P, Helsen MM, Jacobs MJ, Goldman M and van den Berg WB: Role of interleukin-4 and interleukin-10 in murine collagen-induced arthritis. Protective effect of interleukin-4 and interleukin-10 treatment on cartilage destruction. Arthritis Rheum 40: 249-260, 1997. 